\title{
Proof of concept non-invasive estimation of peripheral venous oxygen saturation
}

\author{
Musabbir Khan ${ }^{1 *}$, Chris G. Pretty ${ }^{1}$, Alexander C. Amies', Joel Balmer', Houda E. Banna², Geoffrey M. Shaw ${ }^{2}$ \\ and J. Geoffrey Chase ${ }^{1}$
}

*Correspondence:

musabbir.khan@

pg.canterbury.ac.nz

${ }^{1}$ Centre for Bioengineering,

Department of Mechanical

Engineering, University

of Canterbury, Private Bag

4800, Christchurch 8140,

New Zealand

Full list of author information

is available at the end of the

article

\begin{abstract}
Background: Pulse oximeters continuously monitor arterial oxygen saturation. Continuous monitoring of venous oxygen saturation $\left(\mathrm{SvO}_{2}\right)$ would enable real-time assessment of tissue oxygen extraction $\left(\mathrm{O}_{2} \mathrm{E}\right)$ and perfusion changes leading to improved diagnosis of clinical conditions, such as sepsis.

Methods: This study presents the proof of concept of a novel pulse oximeter method that utilises the compliance difference between arteries and veins to induce artificial respiration-like modulations to the peripheral vasculature. These modulations make the venous blood pulsatile, which are then detected by a pulse oximeter sensor. The resulting photoplethysmograph (PPG) signals from the pulse oximeter are processed and analysed to develop a calibration model to estimate regional venous oxygen saturation $\left(\mathrm{SpvO}_{2}\right)$, in parallel to arterial oxygen saturation estimation $\left(\mathrm{SpaO}_{2}\right)$. A clinical study with healthy adult volunteers $(n=8)$ was conducted to assess peripheral $\mathrm{SvO}_{2}$ using this pulse oximeter method. A range of physiologically realistic $\mathrm{SvO}_{2}$ values were induced using arm lift and vascular occlusion tests. Gold standard, arterial and venous blood gas measurements were used as reference measurements. Modulation ratios related to arterial and venous systems were determined using a frequency domain analysis of the PPG signals.
\end{abstract}

Results: A strong, linear correlation $\left(r^{2}=0.95\right)$ was found between estimated venous modulation ratio $\left(R_{v e n}\right)$ and measured $\mathrm{SvO}_{2}$, providing a calibration curve relating measured $R_{\text {ven }}$ to venous oxygen saturation. There is a significant difference in gradient between the $\mathrm{SpvO}_{2}$ estimation model $\left(\mathrm{SpvO}_{2}=111-40.6^{*} \mathrm{R}\right)$ and the empirical $\mathrm{SpaO}_{2}$ estimation model $\left(\mathrm{SpaO}_{2}=110-25^{*} \mathrm{R}\right)$, which yields the expected arterial-venous differences. Median venous and arterial oxygen saturation accuracies of paired measurements between pulse oximeter estimated and gold standard measurements were 0.29 and $0.65 \%$, respectively, showing good accuracy of the pulse oximeter system.

Conclusions: The main outcome of this study is the proof of concept validation of a novel pulse oximeter sensor and calibration model to assess peripheral $\mathrm{SvO}_{2}$, and thus $\mathrm{O}_{2} \mathrm{E}$, using the method used in this study. Further validation, improvement, and application of this model can aid in clinical diagnosis of microcirculation failures due to alterations in oxygen extraction.

Keywords: Non-invasive, Pulse oximeter, Photoplethysmograph, $\mathrm{SvO}_{2}$ estimation, Artificial modulation 


\section{Background}

Arterial oxygen saturation $\left(\mathrm{SaO}_{2}\right)$ and venous oxygen saturation $\left(\mathrm{SvO}_{2}\right)$ are the two basic parameters used to assess the oxygen delivery process and monitor oxygen extraction $\left(\mathrm{O}_{2} \mathrm{E}\right)$. These two parameters are important for the analysis of whole body oxygen circulation. $\mathrm{O}_{2} \mathrm{E}$ data could provide an indicator of the adequacy of local tissue perfusion, to aid in the early diagnosis of microcirculatory dysfunction in medical conditions, such as in sepsis and cardiogenic shock. Thus, continuous monitoring of both $\mathrm{SaO}_{2}$ and $\mathrm{SvO}_{2}$ would be useful for haemodynamic and perfusion management in clinical settings, according to recent clinical consensus statements [1].

$\mathrm{SaO}_{2}$ can be non-invasively and reliably estimated by pulse oximeters $\left(\mathrm{SpaO}_{2}\right)$, using photoplethysmograph (PPG) signals produced by an optical sensor, typically mounted on a finger, toe, or ear-lobe, to detect blood volume changes. The PPG waveform results from the pulsatile variation in the tissue optical density produced by the pulsation of arterial blood [2,3]. Conventional pulse oximetry relies on the pulsatile nature of arterial blood and differential absorption of oxyhaemoglobin and de-oxyhaemoglobin at red (RD) and infrared (IR) wavelengths to estimate $\mathrm{SpaO}_{2}[4,5]$.

Venous blood in the periphery is typically non-pulsatile in nature. Being dependent on pulsatile blood volume changes to make measurements, conventional pulse oximeter sensors can only determine $\mathrm{SpaO}_{2}$. Thus, $\mathrm{SvO}_{2}$ estimation cannot be provided by conventional pulse oximeters $\left(\mathrm{SpvO}_{2}\right)$. Currently, no available commercial equipment provides continuous, non-invasive measurement or estimate of $\mathrm{SvO}_{2}$.

Reliable $\mathrm{SvO}_{2}$ monitoring is an important element of perfusion monitoring and a necessary measure to determine tissue oxygen extraction capability, which can be used as a clinical marker of microcirculatory failures. In addition, continuous monitoring of the difference between $\mathrm{SaO}_{2}$ and $\mathrm{SvO}_{2}$ would enable the tracking of alterations in tissue perfusion, in real-time. These alterations are very common in sepsis patients [6]. Thus, continuous and simultaneous $\mathrm{SpaO}_{2}$ and $\mathrm{SpvO}_{2}$ estimation by pulse oximeter could be used as an indicator of tissue $\mathrm{O}_{2} \mathrm{E}$ and perfusion changes in response to patient condition or treatment.

Prior studies have investigated non-invasive methods using PPG and near infrared spectroscopy (NIRS) sensors to assess $\mathrm{SpvO}_{2}$. However, the results of these studies have not been conclusive, or have not been validated against a reliable measurement. Two previous studies attempted to assess $\mathrm{SpvO}_{2}$ by inducing pulsations to the venous system, but failed to provide physiologically realistic values of $\mathrm{SpvO}_{2}[7,8]$. Some studies reported physiologically realistic $\mathrm{SvO}_{2}$ estimates, but did not validate their results against gold standard measurements [9-12]. Other studies used reference measurement for comparison, but cannot provide continuous and simultaneous measurement of both $\mathrm{SpaO}_{2}$ and $\mathrm{SpvO}_{2}[13,14]$. These limitations of prior studies reduce the clinical applicability of their methods.

Venous walls are significantly thinner and less elastic than arterial walls. In particular, the veins are up to 10-20 times more compliant compared to arteries under low pressure [15-17]. With relatively small changes in pressure, the circulating blood inside the much more compliant veins experiences large volume changes compared to the arteries $[16,18]$. This large compliance difference is what causes the venous blood of the oesophagus regions to modulate at respiratory frequency seen in previous studies $[16,18]$, and 
is illustrated in Fig. 1. Hence, this compliance difference can be exploited to artificially induce modulations at respiratory frequency and low pressure in the venous system, without disturbing arterial blood flow [19], which can be measured using PPG.

This study presents the initial proof of concept for a novel pulse oximeter method to assess peripheral $\mathrm{SpvO}_{2}$, in addition to $\mathrm{SpaO}_{2}$, leveraging this arterial-venous compliance difference. An artificial pulse generation (APG) system was developed to artificially modulate the peripheral venous blood using a digit pressure cuff. These modulations are detected by a pulse oximeter sensor and the resultant PPG signals are extracted for analysis. The measured transmission from the PPG signal related to venous blood and the $\mathrm{SvO}_{2}$ from gold standard blood gas measurement were used to develop a calibration curve. The main outcome of this study is a proof of the concept and a calibration curve to estimate $\mathrm{SpvO}_{2}$ and accuracy of the sensor.

\section{Methods}

\section{APG system development and operation}

An APG system was developed in this study to exploit the significant arterial-venous compliance difference to induce artificial pulsations predominantly in the venous compartment. The complete APG system is shown schematically in Fig. 1. This system uses a pneumatic UDC2.5 (D.E. Hokanson Inc., Bellevue, WA, USA) digit cuff placed at the intermediate phalanges of the middle finger, as shown in Fig. 2, to mechanically modulate venous blood in the finger. By periodically inflating and deflating the digit cuff, an artificial respiration-like pulse can be induced onto the venous blood of the finger.

Inflation/deflation of the digit cuff is controlled by a 3-way solenoid valve (EVT 307-5DZ-02F-Q, SMC, Noblesville, IN, USA). Operation of the solenoid valve is managed by a PC running LabVIEW through a NI cDAQ-9172 (National Instruments, Austin, TX, USA) multifunction data acquisition device (DAQ). The solenoid is switched on and off with square pulses at $0.2 \mathrm{~Hz}$ and $50 \%$ duty cycle. The $0.2 \mathrm{~Hz}$ frequency is close to typical respiratory frequencies to create artificial venous blood modulations, like those previously reported by Walton et al. [9] when detecting natural venous blood modulations in the oesophagus using a PPG sensor.

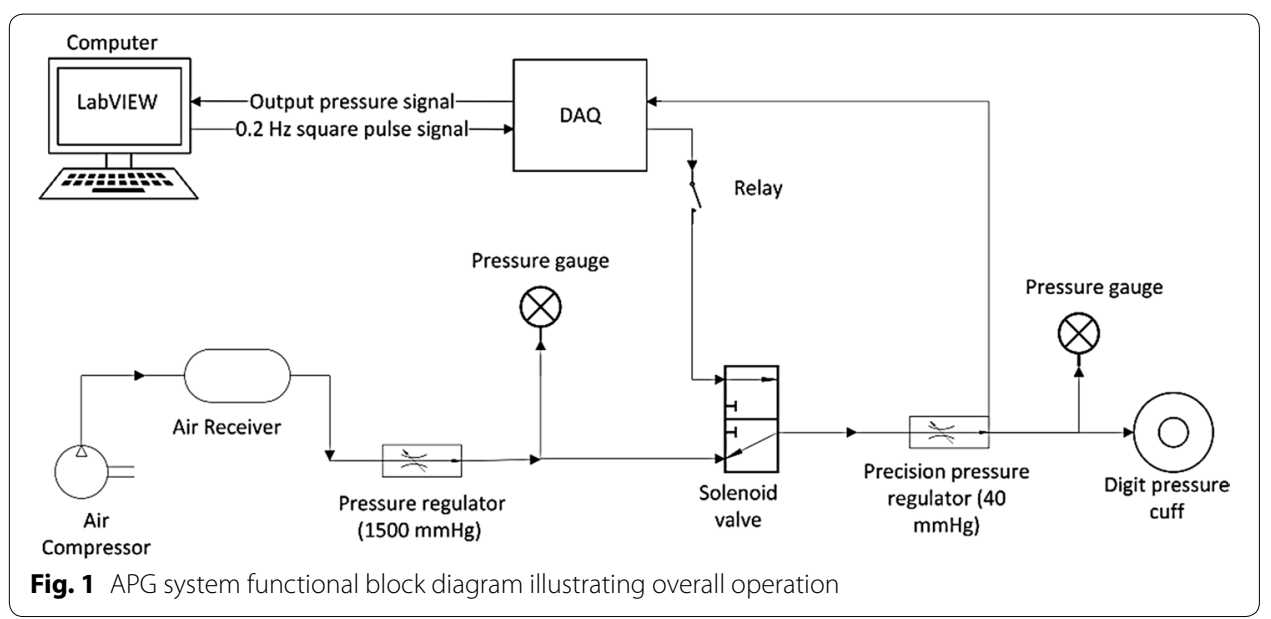




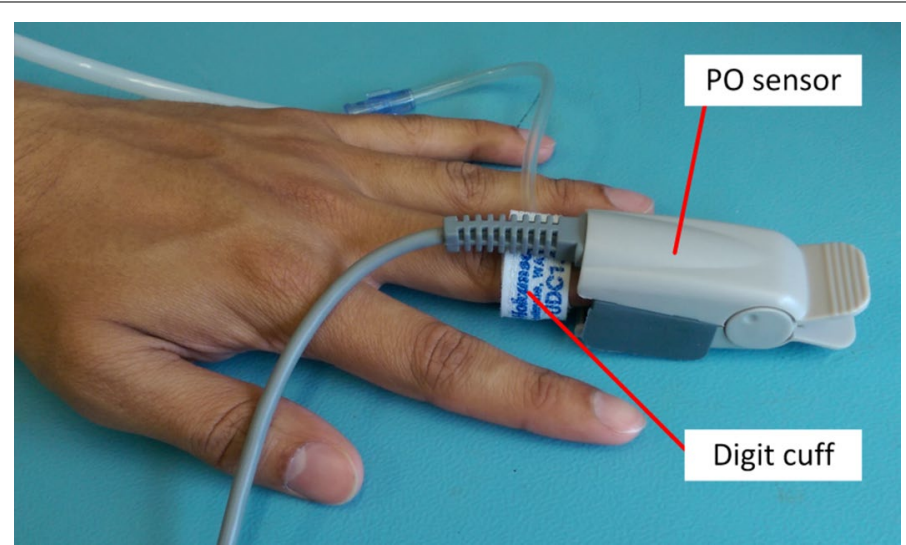

Fig. 2 Digit cuff placement adjacent to the PPG sensor

A precision pressure regulator (AS1002F, SMC, Noblesville, IN, USA) was used to control the pressure of air supplied to inflate the cuff at $40-50 \mathrm{mmHg}$, which is approximately $50 \%$ below typical diastolic arterial pressures. Thus, this cuff compression pressure will predominantly effect the venous compartment. For the deflation portion of the pulse, the air in the cuff was exhausted to the atmosphere with the solenoid valve turning off.

\section{Study cohort}

Ethics approval for this study was granted by the Human Disability an Ethics Committee, New Zealand (Reference: 15/CEN/141). This study was conducted in the intensive care unit (ICU) of St George's Hospital, Christchurch. Eight healthy adult, male, volunteers (aged 23-37 years) with no pre-existing medical conditions were recruited, and provided signed, informed consent. Table 1 provides subject demographics including age, sex, height, weight, body mass index (BMI), resting blood pressure (BP), and resting heart rate (HR). This study was an initial proof of concept testing using healthy adult volunteers and was not about testing full range of people, age, gender or other condition.

\section{Equipment set up}

The equipment for this experiment is shown in Fig. 3 and was set up as follows:

- An arterial catheter (20 or $22 \mathrm{~g}$ ) was inserted into the left radial artery under sterile conditions using a small amount $(0.2 \mathrm{ml})$ of subcutaneous local anaesthetic (lidocaine 1\%). Similarly, a 20-22 g IV catheter was inserted into a vein on the back of the left hand. Both catheters were connected to an 'intraflow' device, which delivered about $3 \mathrm{ml}$ per hour of $0.9 \%$ saline through the arterial catheter. A portable i-Stat1 blood gas analyser (Abbott, Princeton, NJ, USA) was employed to analyse catheter drawn blood samples.

- A standard transmission mode sensor (model: 320701001, Biometric Cables, Guindy, Chennai, India), connected to the custom pulse oximeter (PO) system, was clipped to the index/middle finger of the left hand. 
Table 1 Subject demographics for this study

\begin{tabular}{llllllll}
\hline Subject & Age (years) & Sex & Height $(\mathbf{m})$ & Weight $(\mathbf{k g})$ & BMI & $\begin{array}{l}\text { Resting BP } \\
\text { systolic/diastolic }(\mathbf{m m H g})\end{array}$ & $\begin{array}{l}\text { Resting HR } \\
(\mathbf{b p m})\end{array}$ \\
\hline 1 & 30 & M & 1.75 & 74.40 & 24.16 & $125 / 68$ & 52 \\
2 & 24 & M & 1.78 & 69.00 & 21.78 & $106 / 49$ & 73 \\
3 & 37 & M & 1.83 & 75.00 & 22.40 & $120 / 63$ & 66 \\
4 & 23 & M & 1.71 & 70.00 & 23.94 & $131 / 78$ & 76 \\
5 & 24 & M & 1.68 & 55.00 & 19.49 & $117 / 56$ & 65 \\
6 & 27 & M & 1.68 & 71.50 & 25.51 & $120 / 70$ & 68 \\
7 & 30 & M & 1.80 & 93.00 & 28.70 & $134 / 87$ & 69 \\
8 & 25 & M & 1.70 & 65.00 & 22.49 & $109 / 55$ & 68 \\
\hline
\end{tabular}

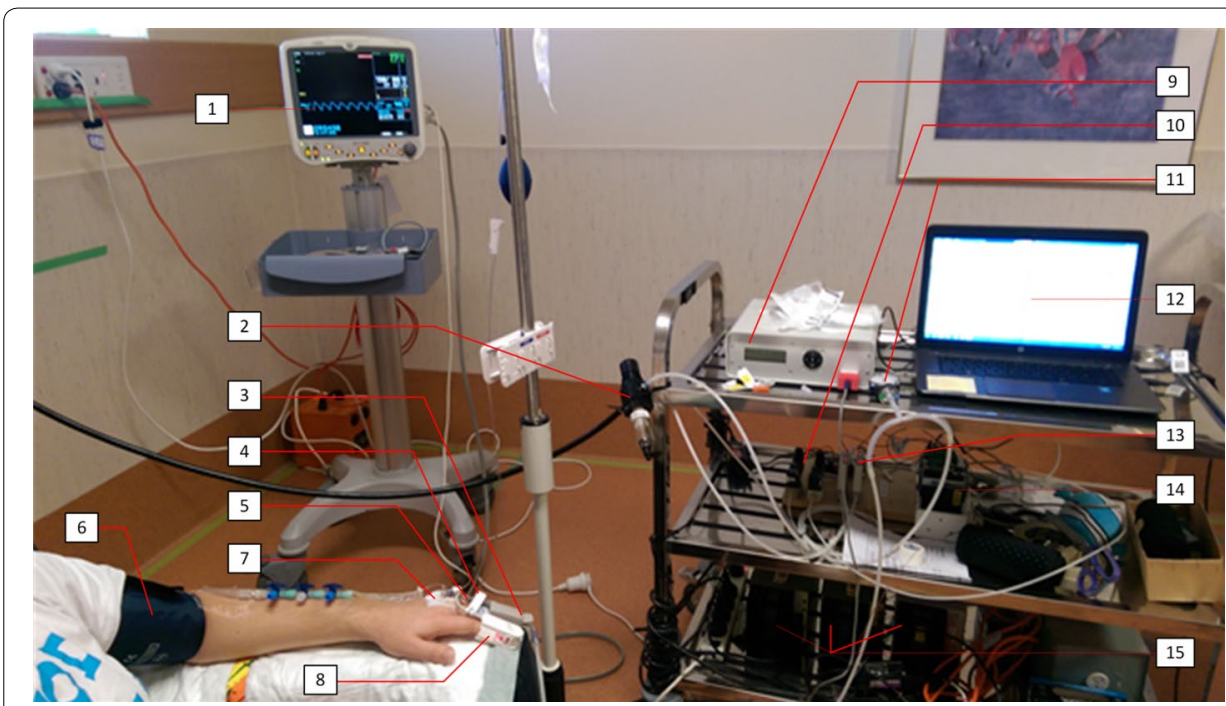

Fig. 3 Typical equipment set up for this study. Key components are labelled. 1 dash monitoring screen, 2 air supply and regulator, $3 \mathrm{PO}$ sensor, 4 thermocouple sensor, 5 digit pressure cuff, 6 blood pressure cuff, 7 venous line and catheter, 8 masimo SET sensor, 9 PO system, 10 solenoid vales, 11 pressure gauge, $12 \mathrm{PC}$ running LABVIEW, 13 ITV001 pressure regulator, 14 NI DAQ system, 15 power supplies

- A Masimo (Masimo Corporation, Irvine, CA, USA) SET pulse oximeter sensor was clipped to the ring finger of the left hand and connected to a portable DASH 5000 (GE Healthcare, Chicago, Illnois, USA) monitoring screen as a reference measurement for $\mathrm{SpaO}_{2}$ and $\mathrm{HR}$.

- A thermocouple was attached next to the PO sensor on the skin surface to continuously monitor digit skin temperature.

- A conventional blood pressure cuff was wrapped around the participant's left forearm to make blood pressure measurements and perform vascular occlusion test (VOT), according to the experimental protocol.

\section{Experimental protocol}

Subjects were asked to refrain from smoking and strenuous physical activities for at least $4 \mathrm{~h}$ prior to the experiment. During the study, subjects were comfortably seated, while resting their left arm on a flat surface at approximately the same height as their heart and 
with minimum movement. During the study, 3 tests were performed to achieve a wide range of $\mathrm{SvO}_{2}$ values and provide a valid dataset.

- At the beginning of the study, resting HR, resting BP, height, weight, and BMI were recorded, as presented in Table 1. Two minutes of baseline PPG data were recorded without any APG activation.

- Subjects were asked to perform the following tests as part of the study protocol:

a. Test 1: Hold left arm at chest level, referred to as baseline.

b. Test 2: Raise left arm above the head for $10 \mathrm{~min}$.

c. Test 3: Allow pressure cuff induced vascular occlusions for 4-6 min using pressures of $170 \mathrm{mmHg}$, which are above typical systolic pressures to stop all flow to the hand.

- $2 \mathrm{ml}$ sample of blood was drawn during each test as follows:

a. Test 1: $1 \times$ arterial sample, $1 \times$ venous sample after $1 \mathrm{~min}$ of APG activation.

b. Test $2: 1 \times$ arterial sample (Subjects $1-5$ only) and $1 \times$ venous sample at $4 \mathrm{~min}$ after the arm was raised.

c. Test 3: $1 \times$ venous sample immediately before the pressure cuff was released, and $1 \times$ venous sample at $30 \mathrm{~s}$ into post occlusion.

Up to a total of 8 blood samples were drawn from each participant. Each blood sample was approximately $2 \mathrm{ml}$ and maximal total blood volume approximately $16 \mathrm{ml}$. The catheters were flushed with $0.9 \%$ saline $(1-3 \mathrm{ml})$ after each blood draw. Subjects 7 and 8 had $2 \times$ venous samples taken during Test 1 to get more baseline measurements and increase the number of overall data samples for analysis.

- APG operation and blood sampling times for the tests are illustrated in Fig. 4:

For Subjects $1-5, \mathrm{SaO}_{2}$ measurements did not vary more than $\pm 1.02 \%$ of the baseline measurements (Test 1 ) for any tests. Since $\mathrm{SaO}_{2}$ unlikely to vary with any change in local conditions for a healthy adult, only one arterial sample was drawn during Test 1 as a reference sample for Subjects $6-8$. Thus, no other arterial samples were obtained during Tests 2 and 3 for Subjects $6-8$ to simplify the study and reduce burden, since the primary goal is to assess the $\mathrm{SvO}_{2}$ provided versus gold standard measures of the same $\mathrm{SvO}_{2}$.

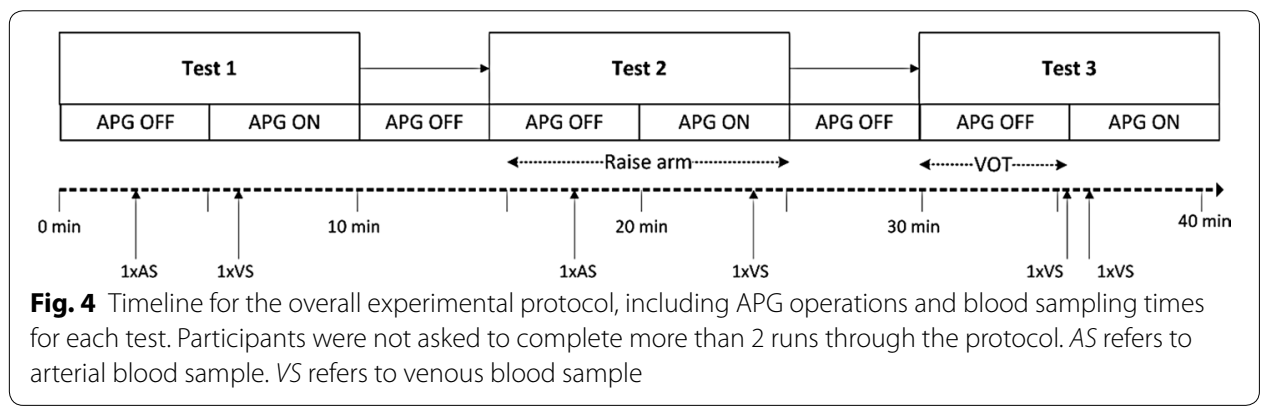


Test 2 was investigated for Subjects 1-5 only to detect any change in $\mathrm{SvO}_{2}$ using the PO sensor and APG system. When the arm is raised above heart level, the mean arterial blood pressure and flow is reduced, and thus a drop in $\mathrm{SvO}_{2}$ can occur. During testing, it proved difficult to reliably draw blood samples with the lowered venous flow and pressure, meaning a range of induced oxygenation levels could not be effectively achieved. Thus, Test 3 was developed to improve reliability and ease of blood sampling for a similar induced change, where it is important to note that inducing a range of oxygenation levels is the only necessity in this initial proof of concept study whose goal is to provide initial validation of the potential to accurately capture a wide range of venous oxygenation levels.

More specifically, Test 3 was conducted as an alternate technique to cause a more repeatable and more easily induced significant drop in $\mathrm{SvO}_{2}$. Several minutes of ischemia is likely to induce a large reduction in overall oxygen saturation, including $\mathrm{SvO}_{2}$, in the ischemic region. It should be noted that Test 3 was repeated for Subjects $6-8$ for 4 and 6 min of vascular occlusions, while Subject 5 being the first for Test 3 was only tested for $4 \mathrm{~min}$ of occlusion as the protocol was still being developed. Thus, Test 3 not only induced a larger $\mathrm{SvO}_{2}$ change but was also more reliable, repeatable, and easier to implement compared to Test 2 .

\section{PPG acquisition and sampling}

PPG finger sensor control and data acquisition were managed with the PO system, which includes serial communication and a graphical interface. The PO system is based on the CY8CKIT-050 PSoC 5LP Development Kit (Cypress Semiconductor, San Jose, CA, USA) that has an ARM Cortex M3 microcontroller. The PPG sensor uses 660 and $940 \mathrm{~nm}$ wavelengths for the RD and IR LEDs, respectively, and a very sensitive photodetector (PD). Feedback control was used by the PO system microcontroller to adjust LED intensities specific to finger thickness.

Light energy received at the PD was converted to current signals and passed through a two stage transimpedance amplifier for signal conditioning. A de-multiplexer splits the conditioned PPG signals so that the RD and IR PPGs are processed independently. Analog PPG signals in the range $0-5 \mathrm{~V}$ were sampled at $50 \mathrm{~Hz}$ by a 16-bit analog-todigital converter (ADC) on the development board. Sampled data were sent to a PC via serial communication and recorded for offline signal processing in MATLAB (R2014a, MathWorks, Natick, MA, USA).

\section{Data processing and analysis}

A two-stage digital filter system was implemented to extract the PPG signals of interest from the raw and amplified PPG data. Zero phase (forward-reverse) filtering was applied at each filter stage to reduce phase distortion and maintain PPG waveform shape.

The first filter stage was a 170th order, equiripple, low-pass, FIR filter with a cut-off frequency of $10 \mathrm{~Hz}$ and attenuation of $50 \mathrm{~dB}$ to effectively remove any unwanted, high frequency noise from the PPG signals [20]. The second filter stage had three parallel filters to separately extract high frequency (AC), APG modulated frequency (APG), and very low frequency (DC) signals. An empirically derived 4th order band-pass, Butterworth, 
IIR filter extracted AC signals, such as the cardiac frequencies, with pass band frequencies of $0.67-4.5 \mathrm{~Hz}$. An empirically derived 12th order band-pass, Butterworth, IIR filter extracted APG signals with pass band frequencies of $0.15-0.67 \mathrm{~Hz}$. An empirically derived 6th order low-pass, Butterworth, IIR filter with a cut-off frequency of $0.15 \mathrm{~Hz}$ was used to extract DC signals between 0 and $0.15 \mathrm{~Hz}$.

A Fast Fourier Transform (FFT) analysis was used to determine the relative power in each part of the PPG signal to calculate the "modulation ratios" ( $\mathrm{R}$ values):

$$
\begin{aligned}
& R_{A r t}=\frac{\left(|A C|_{H R} /|D C|_{O H z}\right)_{R D}}{\left(|A C|_{H R} /|D C|_{O H z}\right)_{I R}} \\
& R_{V e n}=\frac{\left(|A P G|_{0.2 H z} /|D C|_{O H z}\right)_{R D}}{\left(|A P G|_{0.2 H z} /|D C|_{O H z}\right)_{I R}}
\end{aligned}
$$

where,

- $\mathrm{R}_{\text {Art }}$ is the modulation ratio related to arterial blood.

- $\mathrm{R}_{\mathrm{Ven}}$ is the modulation ratio related to venous blood.

- $|\mathrm{AC}|_{\mathrm{HR}}$ is the peak Fourier magnitude of the AC signal, related to cardiac frequency.

- $|\mathrm{APG}|_{0.2 \mathrm{~Hz}}$ is the peak Fourier magnitude at $0.2 \mathrm{~Hz}$ of the APG signal.

- $|\mathrm{DC}|_{\mathrm{OHz}}$ is the peak Fourier magnitude at $0 \mathrm{~Hz}$ frequency of the DC signal.

The fundamental frequency associated with the peak magnitude was identified from the frequency power spectra of AC, APG, and DC offset signals, as shown in Fig. 5. Equations 1 and 2 were then used to compute values of $R_{A r t}$ and $R_{V e n}$. Frequency power spectra were obtained using the FFT on PPG data blocks of $20 \mathrm{~s}$ duration ( $\mathrm{n}=1000$ samples), yielding a frequency resolution of $0.025 \mathrm{~Hz}$. Each $20 \mathrm{~s}$ block corresponded to a blood sample, enabling comparison between measured and estimated saturation values. Blocks of $20 \mathrm{~s}$ were short enough to allow analysis of transient effects in Test 3, while still providing good frequency resolution.

A linear model was fitted to the calculated $\mathrm{R}_{\mathrm{Ven}}$ values and measured blood gas $\mathrm{SvO}_{2}$, and the coefficient of determination $\left(r^{2}\right)$ was computed to assess the strength of their correlation. The linear model was then used as the calibration curve to estimate $\mathrm{SpvO}_{2}$ for each $R_{V e n}$. The Wilcoxon signed rank test was used to compare paired values of measurements, including $\mathrm{R}_{\mathrm{Ven}}$ and $\mathrm{R}_{\text {Art }}$ for each subject, over the experimental cohort. $p$ values of $p<0.05$ were considered statistically significant.

Error propagation analysis, using linear and non-linear combinations [21], was implemented to calculate uncertainties for measured $\mathrm{SvO}_{2}\left(\delta \mathrm{SvO}_{2}\right)$ and $\mathrm{R}_{\mathrm{Ven}}\left(\delta \mathrm{R}_{\mathrm{Ven}}\right)$. The clinical data defined in the Abbott i-Stat1 device manual [22] and the uncertainty of the PO sensor for $\mathrm{SpaO}_{2}$ measurement $[23,24]$ were used in the analysis.

\section{Results}

\section{Detection of AC and APG signals from PPG}

Figure 6 shows an example of the post-processed PPG signals detected by the PO sensor, in the time domain, during Test 1. During the first $120 \mathrm{~s}$ of Test 1, the APG signal was 

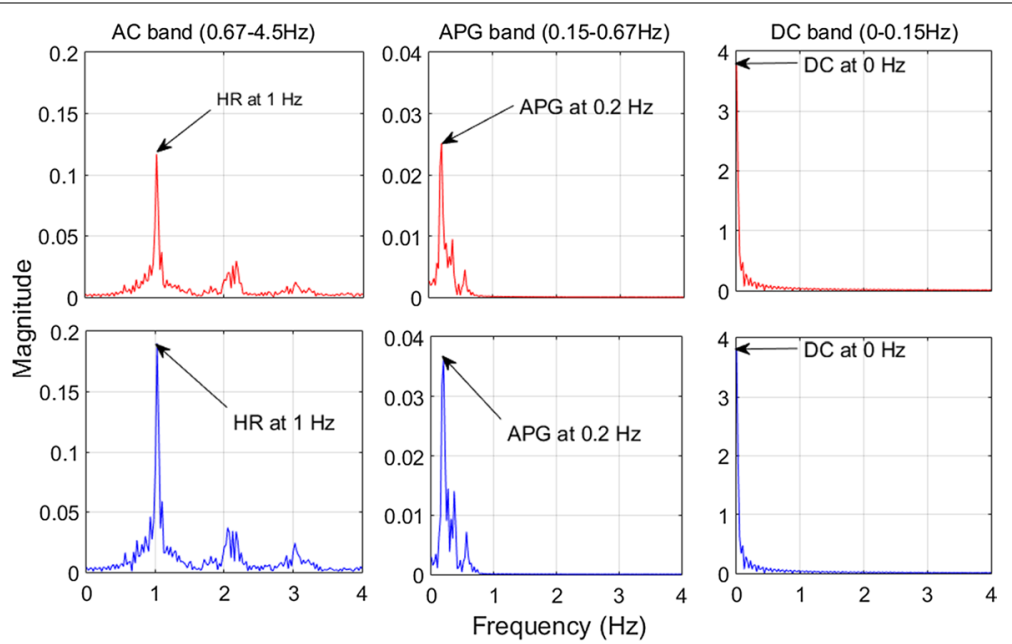

Fig. 5 Frequency power spectrums of the AC, APG, and DC filter bands for Subject 7 from Test 1. Top panels: $\mathrm{RD}$ and bottom panels: IR

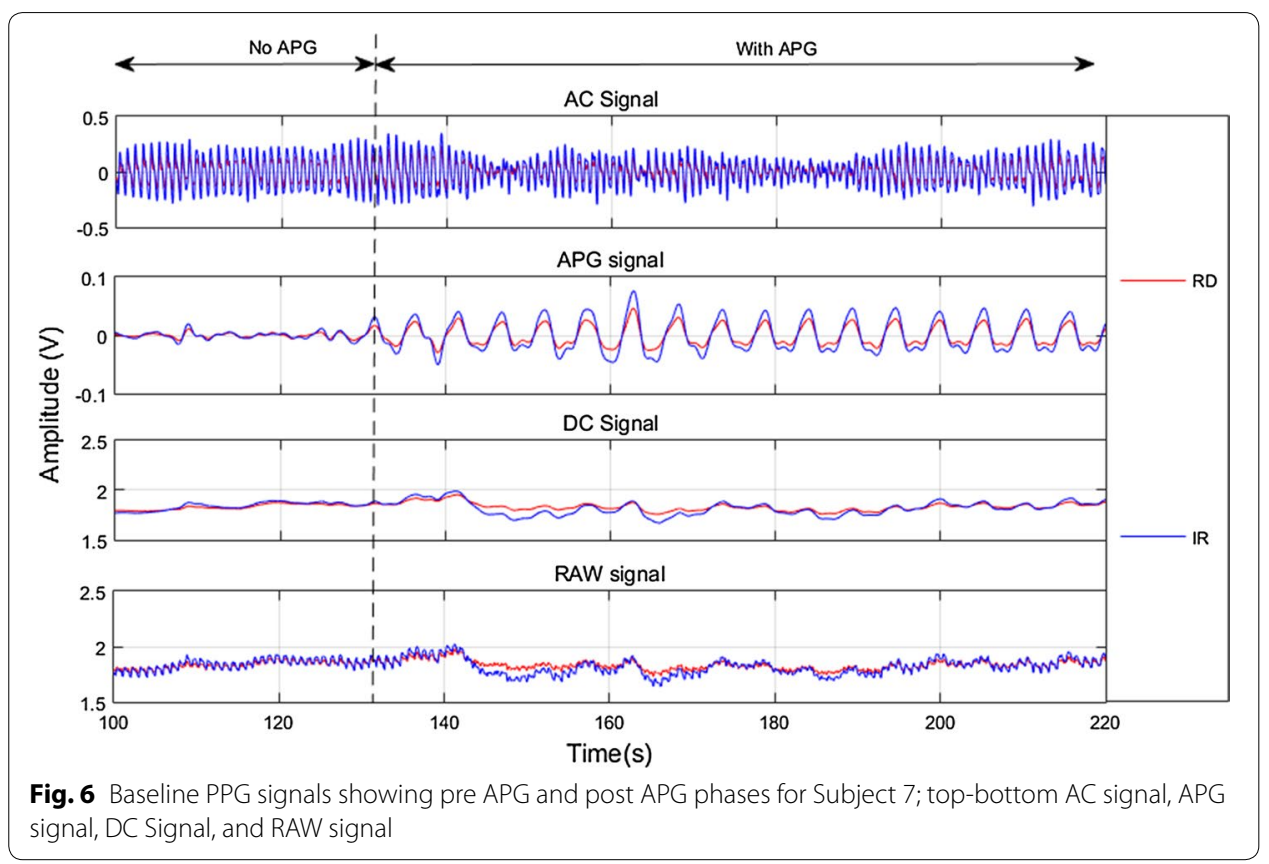

effectively constant since the APG system was not activated, while the AC signal pulsed due to the cardiac cycle. Upon activation of the APG system at approximately $130 \mathrm{~s}$, the APG signal showed a period oscillation with an amplitude of up to $0.06 \mathrm{~V}$.

\section{Correlation between $\mathrm{R}_{\mathrm{ven}}$ and $\mathrm{SvO}_{2}$}

Table 2 presents all the estimated $\mathrm{R}_{\mathrm{Ven}}$ values and measured blood gas $\mathrm{SvO}_{2}$ samples, including their estimated uncertainties, for each subject in all the tests $(n=21)$. The correlation between these two measurements is shown in Fig. 7. A strong, negative correlation is found between the two measurements, with $r^{2}=0.95$. The linear model fitted 


\begin{tabular}{|c|c|c|c|c|}
\hline Subject & $R_{\text {Ven }}$ & $\delta \mathrm{R}_{\text {Ven }}$ & $\mathrm{SvO}_{2} \%$ & $\delta \mathrm{SvO}_{2}$ \\
\hline \multirow[t]{2}{*}{1} & 0.64 & 0.03 & 82.00 & 3.99 \\
\hline & 0.70 & 0.03 & 79.00 & 3.85 \\
\hline 2 & 0.55 & 0.02 & 91.00 & 4.43 \\
\hline \multirow[t]{2}{*}{3} & 0.63 & 0.03 & 82.00 & 3.99 \\
\hline & 0.52 & 0.02 & 91.00 & 4.43 \\
\hline \multirow[t]{2}{*}{4} & 0.87 & 0.04 & 76.00 & 3.70 \\
\hline & 0.97 & 0.04 & 74.00 & 3.60 \\
\hline \multirow[t]{3}{*}{5} & 0.43 & 0.02 & 94.00 & 4.58 \\
\hline & 0.46 & 0.02 & 93.00 & 4.53 \\
\hline & 1.07 & 0.05 & 64.00 & 3.12 \\
\hline \multirow[t]{3}{*}{6} & 0.68 & 0.03 & 82.00 & 3.99 \\
\hline & 1.23 & 0.05 & 59.00 & 2.87 \\
\hline & 1.70 & 0.07 & 42.00 & 2.05 \\
\hline \multirow[t]{4}{*}{7} & 0.71 & 0.03 & 83.00 & 4.04 \\
\hline & 0.62 & 0.03 & 85.00 & 4.14 \\
\hline & 0.79 & 0.03 & 78.00 & 3.80 \\
\hline & 1.24 & 0.05 & 66.00 & 3.21 \\
\hline \multirow[t]{4}{*}{8} & 0.67 & 0.03 & 88.00 & 4.29 \\
\hline & 0.47 & 0.02 & 92.00 & 4.48 \\
\hline & 0.99 & 0.04 & 77.00 & 3.75 \\
\hline & 1.17 & 0.05 & 59.00 & 2.87 \\
\hline
\end{tabular}

through the data points shows a good association between $\mathrm{R}_{\mathrm{Ven}}$ and $\mathrm{SvO}_{2}$ and explains all but $5 \%$ of the variation. In addition, the gradient $(-40.5 \%)$ of this model is different to the gradient $(-25.0 \%)$ of the empirical $\mathrm{SpaO}_{2}$ estimation model commonly used in pulse oximeter estimation [25] and shown on Fig. 7 for comparison.

Most of the data points are in close proximity to the fitted linear model. The data point at $\mathrm{R}=1.7, \mathrm{SvO}_{2}=42 \%$ could have some influence on the liner fit due to its distance from the other points. In this case, exclusion of this point still shows a strong correlation $\left(r^{2}=0.92\right)$ between the two measured and calculated values, indicating the point does not significantly affect the overall correlation.

\section{Measured and estimated data}

Table 3 summarizes all measured and estimated oxygen saturation values, including their paired differences, and $\mathrm{R}$ values for the three tests. Using the empirical pulse oximeter calibration equation for $\mathrm{SpaO}_{2}$, shown in Fig. 7, the median difference between $\mathrm{SaO}_{2}$ and $\mathrm{SpaO}_{2}$ was 0.65 [Inter Quartile Range (IQR) -0.98 to $1.51 \%$ ] . The median difference between $\mathrm{SvO}_{2}$ and $\mathrm{SpvO}_{2}$, determined using the calibration equation derived for $\mathrm{SvO}_{2}$ developed in this study, was just 0.29 [IQR -2.05 to $1.27 \%$ ]

The $\mathrm{R}_{\mathrm{Ven}}$ determined across all the subjects for each protocol were lower and significantly different $(p<0.001)$ to the corresponding $\mathrm{R}_{\text {Art }}$, as expected. The overall median difference between estimated $\mathrm{SpaO}_{2}$ and $\mathrm{SpvO}_{2}$ across the 3 tests was $13.8 \%$, and positive, as expected. In addition, the difference between pairs of measurements in each subject was statistically significant $(p<0.001)$. 


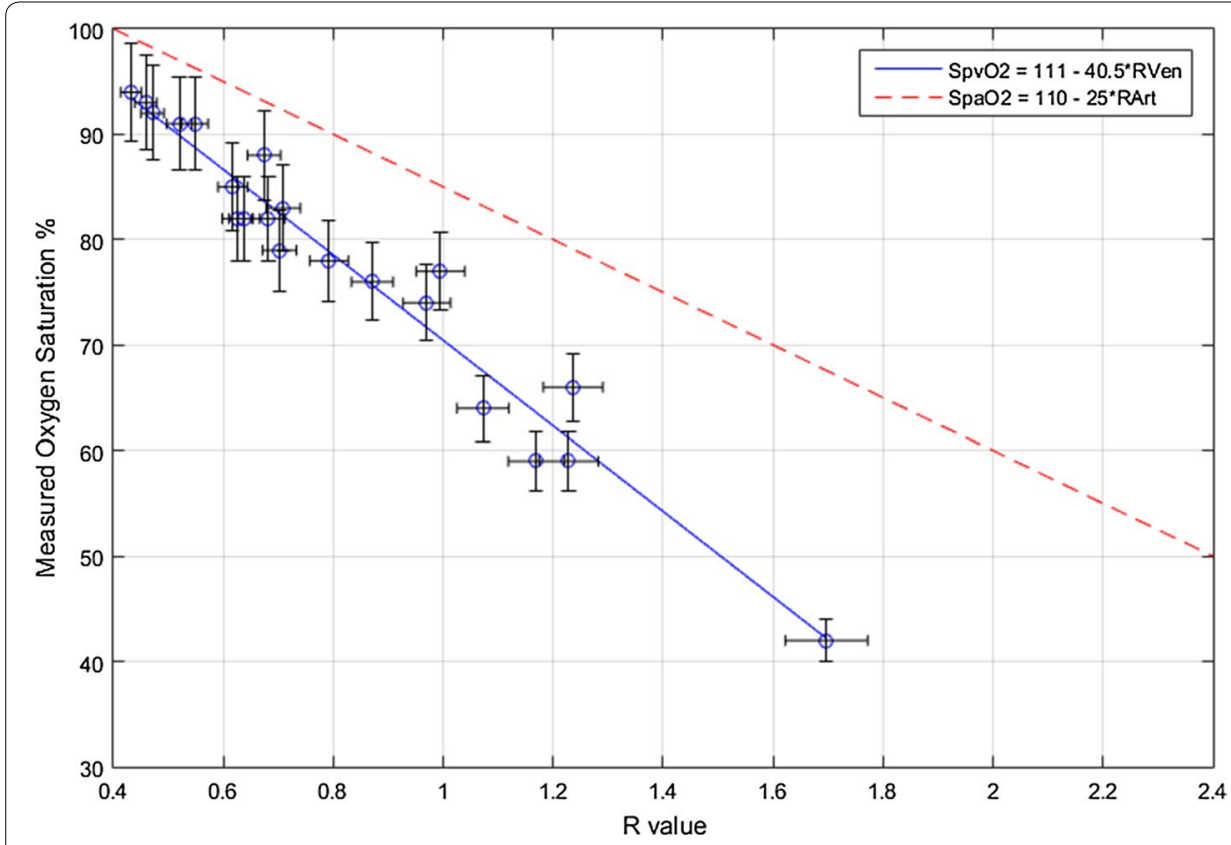

Fig. 7 Correlation $\left(r^{2}=0.95\right)$ between all estimated $\mathrm{R}_{\mathrm{ven}}$ and measured $\mathrm{SvO}_{2}$ samples across the whole cohort from the 3 tests. The solid blue line is the proposed $\mathrm{SpvO}_{2}$ calibration model and the dashed red line is the empirical $\mathrm{SpaO}_{2}$ calibration model related to $\mathrm{R}_{\text {Art }}$ [25]

\section{Discussion}

This study demonstrates that peripheral $\mathrm{SvO}_{2}$ can be reliably and accurately estimated using the PO and APG systems, described, and the calibration curve presented. Very good correlation is found between estimated $\mathrm{R}_{\mathrm{Ven}}$ and measured $\mathrm{SvO}_{2}$ across all the subjects in the 3 tests $\left(r^{2}=0.95\right)$ across a wide range of $\mathrm{SvO}_{2}$ values, as shown in Fig. 7. The negative correlation is expected and in accordance to the empirically derived $\mathrm{R}_{\text {Art }}$ value and measured $\mathrm{SaO}_{2}$ in other studies [25-27]. This relationship allows determination of $\mathrm{SvO}_{2}$ from $\mathrm{R}_{\mathrm{Ven}}$, as obtained using the APG system. Thus, the linear fit and very high $r^{2}$ value indicates the applicability of the metric in assessment of $\mathrm{SvO}_{2}$ and $\mathrm{O}_{2} \mathrm{E}$ in future studies.

Using this calibration model, the median (IQR) difference between pairs of measured and estimated venous oxygen saturation values was calculated to be $0.29 \%[-2.05$ to $1.27 \%]$, which is less than the measurement error from the reference i-Stat blood gas analyzer. Using the empirical pulse oximeter calibration model, the median [IQR] difference between pairs of measured and estimated arterial oxygen saturation values was calculated to be $0.65 \%$ [ -0.98 to $1.51 \%$. Thus, venous oxygen saturation accuracies from this pulse oximeter system are expected to be similar to those commonly obtained for arterial oxygen saturations.

The relationship between the PPG signal modulation ratio (R) and the oxygen saturation is associated with the bulk tissue's optical properties. Modulation induced artefacts can have a measurable impact on the relative optical properties of the tissue medium being investigated using PPG [28]. Such artefacts in a limb may simulate the effects of tissue hemoglobin concentration variations of the tissues medium. These variations can 
Table 3 Measured and estimated data for all the subjects across the three tests

\begin{tabular}{|c|c|c|c|c|c|c|c|c|c|}
\hline Test & $\begin{array}{l}\text { Sub- } \\
\text { ject }\end{array}$ & $\mathbf{R}_{\text {Ven }}$ & $\mathrm{SpvO}_{2} \%$ & $\mathrm{SvO}_{2} \%$ & $\mathrm{SvO}_{2-} \mathrm{SpvO}_{2} \%$ & $\mathrm{R}_{\text {Art }}$ & $\mathrm{SpaO}_{2} \%$ & $\mathrm{SaO}_{2} \%$ & $\mathrm{SaO}_{2}-\mathrm{SpaO}_{2} \%$ \\
\hline \multirow[t]{10}{*}{1} & 1 & 0.64 & 84.97 & 82 & -2.97 & 0.56 & 96.02 & 97 & 0.98 \\
\hline & 2 & 0.55 & 88.6 & 91 & 2.4 & 0.52 & 96.91 & 98 & 1.09 \\
\hline & 3 & 0.63 & 85.45 & 82 & -3.45 & 0.58 & 95.62 & 98 & 2.38 \\
\hline & 4 & 0.87 & 75.5 & 76 & 0.5 & 0.55 & 96.16 & 96 & -0.16 \\
\hline & 5 & 0.43 & 93.32 & 94 & 0.68 & 0.48 & 98 & 97 & -1 \\
\hline & 6 & 0.68 & 83.2 & 82 & -1.2 & 0.47 & 98.16 & 97 & -1.16 \\
\hline & 7 & 0.71 & 82.08 & 83 & 0.92 & 0.63 & 94.34 & 97 & 2.66 \\
\hline & & 0.62 & 85.83 & 85 & -0.83 & 0.58 & - & - & - \\
\hline & 8 & 0.67 & 83.5 & 88 & 4.5 & 0.57 & 95.74 & 97 & 1.26 \\
\hline & & 0.47 & 91.71 & 92 & 0.29 & 0.53 & - & - & - \\
\hline \multirow[t]{4}{*}{2} & 1 & 0.7 & 82.35 & 79 & -3.35 & 0.53 & 96.87 & 99 & 2.13 \\
\hline & 3 & 0.52 & 89.73 & 91 & 1.27 & 0.47 & 98.2 & 97 & -1.2 \\
\hline & 4 & 0.97 & 71.53 & 74 & 2.47 & 0.52 & 97.02 & 96 & -1.02 \\
\hline & 5 & 0.46 & 92.2 & 93 & 0.8 & 0.48 & 97.91 & 97 & -0.91 \\
\hline \multirow[t]{7}{*}{3} & 5 & 1.07 & 67.39 & 64 & -3.39 & 0.69 & - & - & - \\
\hline & 6 & 1.23 & 61.05 & 59 & -2.05 & 0.7 & - & - & - \\
\hline & & 1.7 & 42.08 & 42 & -0.08 & 0.68 & - & - & - \\
\hline & 7 & 0.79 & 78.73 & 78 & -0.73 & 0.52 & - & - & - \\
\hline & & 1.24 & 60.75 & 66 & 5.25 & 0.76 & - & - & - \\
\hline & 8 & 0.99 & 70.5 & 77 & 6.5 & 0.55 & - & - & - \\
\hline & & 1.17 & 63.46 & 59 & -4.46 & 0.62 & - & - & - \\
\hline \multicolumn{2}{|c|}{ Median } & 0.7 & 82.35 & 82 & 0.29 & 0.55 & 96.77 & 97 & 0.65 \\
\hline \multicolumn{2}{|c|}{$\begin{array}{l}\text { Interquartile } \\
\text { range }\end{array}$} & $\begin{array}{c}0.62 \text { to } \\
0.99\end{array}$ & $\begin{array}{c}70.50 \text { to } \\
85.83\end{array}$ & $\begin{array}{c}74.00 \text { to } \\
88.00\end{array}$ & -2.05 to 1.27 & $\begin{array}{c}0.52 \text { to } \\
0.62\end{array}$ & $\begin{array}{c}95.81 \text { to } \\
97.69\end{array}$ & $\begin{array}{c}97.00 \text { to } \\
97.00\end{array}$ & -0.98 to 1.51 \\
\hline
\end{tabular}

Some subjects do not have measured values as explained in "Experimental protocal". SpaO ${ }_{2}$ estimated using $110-25 * \mathrm{R}_{\text {Art }}$ and $\mathrm{SvO}_{2}$ estimated using $111-40.5 * \mathrm{R}_{\text {ven }}$

result in different $\mathrm{R}$ values derived from PPG measurements when compared to nonmodulated PPG measurements, as seen in previous studies [28, 29].

The good relationship between $\mathrm{R}_{\mathrm{Ven}}$ and $\mathrm{SvO}_{2}$ obtained in this study suggest the low pressure external modulations caused by the APG system impacted almost exclusively the venous system, due to the significant arterial-venous compliance difference. Therefore, $R_{\text {Ven }}$ values derived from the APG and DC offset signals are different to $R_{\text {Art }}$ values derived from the $\mathrm{AC}$ and $\mathrm{DC}$ offset signals.

When the arm is completely occluded above systolic blood pressures, arterial blood supply to the arm is stopped. During Test 3 , the arm was occluded and blood flow to the arm was restricted for several minutes. Without any perfusion it is expected that the occluded blood will slowly desaturate of oxygen over time [30-33]. The oxygen present in the occluded blood will gradually diffuse to nearby tissues due to the hypoxic condition created by low oxygen tension or $\mathrm{PO}_{2}$ in the occluded region. Hence, the lower $\mathrm{SpvO}_{2}$ and $\mathrm{SpaO}_{2}$ values in Test 3 and Table 3.

In Test 3 , a venous sample was taken immediately before the arm pressure cuff was completely deflated to get a measure of the true ischemic, oxygen desaturated blood. The APG was activated just before releasing the pressure cuff, and thus, the first few APG pulses capture the true ischemic blood. The APG pulse amplitude of the RD signal was 
expected to be greater than the IR signal during such low saturation phase [34, 35]. This effect in the time domain PPG signals also has an equal effect to the PPG signals in the frequency domain. Thus, higher than baseline $R_{\text {Ven }}$ values are observed in the Recovery 1 phase of Test 3. In addition, due to the greater inaccuracy of the wavelengths used at saturation $<70 \%$ [29], the error in measurement is also larger for those $\mathrm{R}_{\text {Ven }}$ values.

During the occlusion phase of Test 3, the local tissue was being deprived of oxygen by the lack of perfusion. Previous studies have shown that tissues will temporarily increase extraction of oxygen from blood to return to normal tissue saturation level after ischemia $[31,36,37]$. Thus, when the cuff is released after this brief ischemia the local tissues and muscles in the arm increased extraction of oxygen, which is evident across all the subjects in Test 3 , as seen in Table 3.

The recovery of oxygen desaturated blood to baseline oxygen saturation level after ischemia is very rapid during reactive hyperemia in healthy adults [30,33]. For Subjects 5 and 6, a venous sample was taken approximately $30 \mathrm{~s}$ after blood flow was restored to the arm. Blood gas analysis of those samples revealed $\mathrm{SvO}_{2}$ had already returned to baseline level. Thus, the rapid change from low saturation to normal occurred in less than $30 \mathrm{~s}$. However, this tissue oxygen restoration time can be significantly greater due to attenuated reactive hyperaemia in case of patients with sepsis as reported by previous studies [30, 38-41]. Hence, it is important to capture and track such changes in realtime for haemodynamic and perfusion monitoring.

No significant changes in $\mathrm{SvO}_{2}$ from baseline were observed due to lifting the arm in Test 2. These findings suggest variations in peripheral $\mathrm{SvO}_{2}$ and $\mathrm{O}_{2} \mathrm{E}$ are not influenced by reduction in peripheral arterial blood flow induced in this test. In particular, one subject in Test 2 showed elevated $\mathrm{SvO}_{2}$, for causes yet to be determined. However, possible reasons include; (1) increased temperature of the hand to arterialise the venous blood; (2) increased vasodilation of peripheral arteries to improve blood flow conditions; or (3) over reaction to loss of blood flow.

In addition, Test 2 posed several challenges. First, it was difficult to draw blood when the hand was held up, due to reduced venous flow and pressure. Second, a tourniquet was employed to increase venous blood volume for sampling, which may have obstructed venous flow in the periphery. Hence, Test 3 was later developed to replace Test 2 and ensure a robust, reliable, and large $\mathrm{SvO}_{2}$ change. However, the data from Test 2 still provided useful for development of the $\mathrm{SpvO}_{2}$ calibration model, and was thus kept.

\section{Limitations of this study}

The primary limitation of this study is the relatively small number $(n=21)$ of data points from a male cohort used to develop the $\mathrm{SpvO}_{2}$ calibration curve. More data points from a gender balanced, larger, and diverse cohort will add robustness to the overall result. However, the very strong correlation obtained indicates the concept should generalize well.

In particular, this study is only a proof of concept of this pulse oximeter method to show the potential over a range of:

- $\mathrm{SvO}_{2}$ conditions induced to test accuracy across the physiological range.

- Peripheral blood flow levels that might be seen clinically. 
The study was not about testing full range of people or sex or other conditions. This initial test was to show how the concept worked, and quantify how well. Results from this initial proof of concept study justify a complete validation trial with more subjects and a balanced cohort, in terms of age and sex.

\title{
Conclusions
}

This study presents a non-invasive method to induce venous blood modulations using a pneumatic digit cuff $(0.2 \mathrm{~Hz}, 40-50 \mathrm{mmHg}$ inflation pressure), which can be captured by PPG. A novel calibration model was derived from venous blood modulated PPG signals and measured $\mathrm{SvO}_{2}$ to assess $\mathrm{SpvO}_{2}$. A strong, linear correlation $\left(r^{2}=0.95\right)$ was found between estimated $\mathrm{R}_{\mathrm{Ven}}$ and measured $\mathrm{SvO}_{2}$, with the median difference of 0.29\% between pairs of measurement, providing a robust calibration and accurate estimate. In addition, the gradient of this model $(-40.5 \%)$ is different to the gradient of the conventional pulse oximeter calibration model (-25\%). The proposed $\mathrm{SpvO}_{2}$ estimation model can be used as a potential metric and indicator for low $\mathrm{O}_{2} \mathrm{E}$, consumption, and tissue hypoxia.

Real-time estimation of peripheral $\mathrm{SvO}_{-}$, using this novel pulse oximeter method, and $\mathrm{SaO}_{2}$ will enable continuous, real-time monitoring of these physiological conditions. Thus, improvement and application of this novel concept could aid in diagnosis of medical conditions related to microcirculation dysfunction, such as sepsis and cardiac failure, which are both common in the ICU, as well as length of stay, cost, and mortality.

\begin{abstract}
Abbreviations
AC: high frequency component of the PPG signal; ADC: analog-to-digital converter; APG: artificial pulse generation; BP: blood pressure; DC: low frequency component of the PPG signal; FFT: Fast Fourier Transform; FIR: finite impulse response; HDEC: Health and Disability Ethics Committee; HR: heart rate; ICU: intensive care unit; IIR: infinite impulse response; IR: infrared light/wavelength; IV: intravenous; LED: light emitting diode; NIRS: near infrared spectroscopy; $\mathrm{O}_{2} \mathrm{E}$ : oxygen extraction; PPG: photoplethysmograph; PO: pulse oximeter; $R$ : modulation ratio; $R_{\text {Art }}: R$ value derived from $A C$ and $D C$ signals; $R_{V e n}$ : $R$ value derived from APG and DC signals; RBC: red blood cell; RD: red light/wavelength; $\mathrm{SaO}_{2}$ : arterial blood oxygen saturation; $\mathrm{SpO}_{2}$ : pulse oximeter estimated $\mathrm{SaO}_{2} ; \mathrm{SpaO}_{2}$ : custom pulse oximeter estimated $\mathrm{SaO}_{2} ; \mathrm{SvO}_{2}$ : venous blood oxygen saturation; $\mathrm{SpvO}_{2}$ : custom pulse oximeter estimated $\mathrm{SvO}_{2}$; VOT:Vascular Occlusion Test.
\end{abstract}

\section{Authors' contributions}

MK acted as the primary investigator, analysed the clinical data, and wrote this manuscript. CP and JC co-investigated this study, and had significant impact to the writing of this manuscript. AA and JB assisted in conducting the study and sorting the clinical data. GS helped to design this study, and was also the chief co-ordinating officer for this study. GS and HB performed the clinical works, including blood sampling and analysis. All authors read and approved the final manuscript.

\section{Author details}

${ }^{1}$ Centre for Bioengineering, Department of Mechanical Engineering, University of Canterbury, Private Bag 4800, Christchurch 8140, New Zealand. ${ }^{2}$ Department of Intensive Care Unit, Christchurch Hospital, Private Bag 4710, Christchurch 8140 , New Zealand.

\section{Acknowledgements}

The authors would like to thank Nikki Wood and all the nursing staff of the ICU at St George's Hospital for their time and support in this clinical study. We would also like to thank St. Georges for sponsoring this study.

\section{Competing interests}

The authors declare that they have no competing interests.

\section{Availability of data and materials}

The datasets generated during and/or analysed during the current study are not publicly available due to no prior publication but are available from the corresponding author on reasonable request.

\section{Ethics approval and consent to participate}

This study and use of data were approved by the Human Disability and Ethics Committee, New Zealand (Reference: 15/ CEN/141) under the project title "The MOOSE study". A volunteer was included in the study as a subject after informed and signed consent were received. Data were de-identified and securely stored. 


\section{Funding}

Research was funded by the New Zealand Tertiary Education Committee and MedTech Centre of Research and Expertise (CORE). MK was supported by the University of Canterbury Doctoral Scholarship. JB is supported by the MedTech Core and AA by the New Zealand Health and Research Council (HRC). St. George's Hospital partially sponsored the study, and provided nursing support and clinical equipment for blood sample collection and analysis.

\section{Publisher's Note}

Springer Nature remains neutral with regard to jurisdictional claims in published maps and institutional affiliations.

\section{Received: 2 February 2017 Accepted: 13 May 2017}

Published online: 19 May 2017

\section{References}

1. Cecconi M, De Backer D, Antonelli M, Beale R, Bakker J, Hofer C, et al. Consensus on circulatory shock and hemodynamic monitoring. Task force of the European Society of Intensive Care Medicine. Intensiv Care Med. 2014;40:1795-815.

2. Daly SM, Leahy MJ. 'Go with the flow': a review of methods and advancements in blood flow imaging. J Biophotonics. 2013;6:217-55.

3. Aoyagi T. Pulse oximetry: its invention, theory, and future. J Anesth. 2003;17:259-66.

4. Jubran A. Pulse oximetry. In: Hedenstierna G, Mancebo J, Brochard L, Pinsky MR, editors. Applied physiology in intensive care medicine. Berlin: Springer; 2009. p. 45-8.

5. Goldman JM, Petterson MT, Kopotic RJ, Barker SJ. Masimo signal extraction pulse oximetry. J Clin Monit Comput. 2000;16:475-83.

6. Trzeciak S, Dellinger RP, Parrillo JE, Guglielmi M, Bajaj J, Abate NL, et al. Early microcirculatory perfusion derangements in patients with severe sepsis and septic shock: relationship to hemodynamics, oxygen transport, and survival. Ann Emerg Med. 2007;49:88-98.

7. Schoevers J, Scheffer C, Dippenaar R. Low-oxygen-saturation quantification in human arterial and venous circulation. IEEE Trans Biomed Eng. 2009;56:846-54.

8. Echiadis AS, Crabtree VP, Bence J, Hadjinikolaou L, Alexiou C, Spyt TJ, et al. Non-invasive measurement of peripheral venous oxygen saturation using a new venous oximetry method: evaluation during bypass in heart surgery. Physiol Meas. 2007;28:897-911.

9. Walton ZD, Kyriacou PA, Silverman DG, Shelley KH. Measuring venous oxygenation using the photoplethysmograph waveform. J Clin Monit Comput. 2010;24:295-303.

10. Phillips JP, Belhaj A, Shafqat K, Langford RM, Shelley KH, Kyriacou PA. Modulation of finger photoplethysmographic traces during forced respiration: venous blood in motion? Conf Proc IEEE Eng Med Biol Soc. 2012;2012:3644-7.

11. Shafqat K, Langford R, Kyriacou P. Estimation of instantaneous venous blood saturation using the photoplethysmograph waveform. Physiol Meas. 2015;36:2203.

12. Franceschini MA, Boas DA, Zourabian A, Diamond SG, Nadgir S, Lin DW, et al. Near-infrared spiroximetry: noninvasive measurements of venous saturation in piglets and human subjects. J Appl Physiol. 2002;92:372-84.

13. Yoxall C, Weindling A. Measurement of venous oxyhaemoglobin saturation in the adult human forearm by near infrared spectroscopy with venous occlusion. Med Biol Eng Comput. 1997;35:331-6.

14. Nitzan M, Babchenko A, Khanokh B, Taitelbaum H. Measurement of oxygen saturation in venous blood by dynamic near infrared spectroscopy. J Biomed Opt. 2000;5:155-62.

15. Klabunde R. Cardiovascular physiology concepts. 2nd ed. Philadelphia: Lippincott Williams \& Wilkins; 2011

16. Caro CG, Pedley T, Schroter R, Seed W, Parker K. The mechanics of the circulation. 2nd ed. New York: Cambridge University Press; 2012.

17. Wester AL, Dunlop O, Melby KK, Dahle UR, Wyller TB. Age-related differences in symptoms, diagnosis and prognosis of bacteremia. BMC Infect Dis. 2013;13:346.

18. Wardhan R, Shelley K. Peripheral venous pressure waveform. Curr Opin Anaesthesiol. 2009:22:814-21.

19. Groothuis JT, van Vliet L, Kooijman M, Hopman MTE. Venous cuff pressures from $30 \mathrm{mmHg}$ to diastolic pressure are recommended to measure arterial inflow by plethysmography. J Appl Physiol. 2003;95:342-7.

20. Markandey V. Pulse Oximeter Implementation on the TMS320C5515 DSP Medical Development Kit (MDK). 2010. http://www.ti.com/lit/an/sprab37a/sprab37a.pdf. Accessed 1 Nov 2013.

21. Starr ME, Saito H. Sepsis in old age: review of human and animal studies. Aging Dis. 2014;5:126-36.

22. Abbott. i-STAT ${ }^{\circledR} 1$ System Manual. 2013. https://www.abbottpointofcare.com/en-int/support/technical-documentation/istat-system-manuals. Accessed 25 Apr 2016.

23. Batchelder PB, Raley DM. Maximizing the laboratory setting for testing devices and understanding statistical output in pulse oximetry. Anesth Analg. 2007;105:S85-94.

24. Fouzas S, Priftis KN, Anthracopoulos MB. Pulse oximetry in pediatric practice. Pediatrics. 2011;128:740-52.

25. Webster JG. Design of pulse oximeters. London: CRC Press; 2002

26. Tremper KK, Barker SJ. Pulse oximetry. Anesthesiology. 1989;70:98-108.

27. Noninvasive Ross F, Monitoring Optical. The biomedical engineering handbook. 2nd ed. London: CRC Press; 1999.

28. Casciani JR, Mannheimer PD, Nierlich SL, Ruskewicz SJ. Pulse oximeter and sensor optimized for low saturation. US Patent No. 7,415,298, 19 August 2008.

29. Mannheimer PD, Cascini J, Fein ME, Nierlich SL. Wavelength selection for low-saturation pulse oximetry. IEEE Trans Biomed Eng. 1997;44:148-58. 
30. Skarda DE, Mulier KE, Myers DE, Taylor JH, Beilman GJ. Dynamic near-infrared spectroscopy measurements in patients with severe sepsis. Shock. 2007;27:348-53.

31. Lima A, Bakker J. Near-infrared spectroscopy for monitoring peripheral tissue perfusion in critically ill patients. Rev Bras Ter Intensiv. 2011;23:341-51.

32. Futier E, Christophe S, Robin E, Petit A, Pereira B, Desbordes J, et al. Use of near-infrared spectroscopy during a vascular occlusion test to assess the microcirculatory response during fluid challenge. Crit Care. 2011;15:1-10.

33. Gómez H, Torres A, Polanco P, Kim HK, Zenker S, Puyana JC, et al. Use of non-invasive NIRS during a vascular occlusion test to assess dynamic tissue $\mathrm{O}_{2}$ saturation response. Intensiv Care Med. 2008;34:1600-7.

34. N. T. S. NTS. A Technology Overview of the Nellcor ${ }^{\mathrm{T}}$ OxiMax Pulse Oximetry System. 2011. http://www.covidien. com/imageServer.aspx/doc226941.1.2.3_OxiMax\%20whitepaper.pdf?contentID=25496\&contenttype=application/ pdf. Accessed 22 June 2015.

35. Mannheimer PD. The light-tissue interaction of pulse oximetry. Anesth Analg. 2007;105:S10-7.

36. Derdeyn CP, Yundt KD, Videen TO, Carpenter DA, Grubb RL, Powers WJ. Increased oxygen extraction fraction is associated with prior ischemic events in patients with carotid occlusion. Stroke. 1998;29:754-8.

37. Lipcsey M, Woinarski NC, Bellomo R. Near infrared spectroscopy (NIRS) of the thenar eminence in anesthesia and intensive care. Ann Intensiv Care. 2012;2:11.

38. Neviere R, Mathieu D, Chagnon JL, Lebleu N, Millien JP, Wattel F. Skeletal muscle microvascular blood flow and oxygen transport in patients with severe sepsis. Am J Respir Crit Care Med. 1996;153:191-5.

39. Kirschenbaum LA, Astiz ME, Rackow EC, Saha DC, Lin R. Microvascular response in patients with cardiogenic shock. Crit Care Med. 2000;28:1290-4

40. Astiz ME, DeGent GE, Lin RY, Rackow EC. Microvascular function and rheologic changes in hyperdynamic sepsis. Crit Care Med. 1995:23:265-71.

41. Sair M, Etherington PJ, Peter Winlove C, Evans TW. Tissue oxygenation and perfusion in patients with systemic sepsis. Crit Care Med. 2001;29:1343-9.

Submit your next manuscript to BioMed Central and we will help you at every step:

- We accept pre-submission inquiries

- Our selector tool helps you to find the most relevant journal

- We provide round the clock customer support

- Convenient online submission

- Thorough peer review

- Inclusion in PubMed and all major indexing services

- Maximum visibility for your research

Submit your manuscript at www.biomedcentral com/submit 